\title{
Coordinate measuring machine uncertainty analysis using the combinatorial cyclic method of optimization
}

\author{
Analiza dokładności pomiarowej maszyn współrzędnościowych z użyciem \\ kombinatoryczno-cyklicznej metody optymalizacji
}

\author{
STANISŁAW ZIETTARSKI \\ STANISŁAW KACHEL \\ ABDELKADER BENAOUALI *
}

Materiały z XX SKWPWiE, Jurata $2016 \mathrm{r}$. DOI: $10.17814 /$ mechanik.2016.7.216
In this paper, The Combinatorial-Cyclic method of Optimization (CCOpt) is used to inspect the accuracy of a CMM by analyzing the standard deviation of measurements points on a calibration sphere. A software dedicated to perform sphere fitting and error analysis were developed within the frame of the integrated CAD/CAM/CAE system SIEMENS (GRIP).

KEYWORDS: combinatorial-cyclic method, CMM accuracy

W niniejszym artykule zaprezentowano kombinatoryczno-cykliczna metodę optymalizacji, która została wykorzystana do sprawdzenia dokładności maszyny współrzędnościowej poprzez analizę odchylenia standardowego punktów pomiarowych na kuli wzorcowej. Opracowane oprogramowanie dla systemu CAD/CAM/CAE Siemens NX jest przeznaczone do porównywania wzorca z obiektem rzeczywistym celem przeprowadzenia analizy błędów wykonania elementu rzeczywistego.

SŁOWA KLUCZOWE: metody kombinatoryczno-cykliczne, dokładność CMM

Coordinate metrology is a field of metrology that is becoming increasingly popular in the manufacturing industry. Coordinate metrology enables the three-dimensional measurement to be carried out on complex object in a single setup. The instrument used for this purpose is known as the coordinate measuring machine or CMM. CMMs are mechanical systems designed to collect coordinates of points on a work piece surface by moving a measuring probe over it. There are severa physical configurations of CMMs. All the configurations have a method of moving the probe along three axes relative to the object. Although there are many designs of CMMs but they can be grouped into five basic types: Moving Bridge, Fixed Bridge, Cantilever, Horizontal Arm and Gantry type [1].

In this paper, a new method of CMM accuracy verification is presented. This method is based on the Combinatorial-Cyclic method of Optimization (CCOpt) as a replacement of the CMM software to calculate the $(x, y, z)$ coordinates of the reference sphere center and its radius. The standard deviation is used as the accuracy indicator. The experimental tests have been carried out on a CMM ZEISS ACCURA in the Metrology Laboratory of the Department of Construction and Operation of Aircraft at the Military University Of technology.

\section{Overview of the combinatorial-cyclic method of optimization}

The Combinatorial-Cyclic method of Optimization (CCOpt) was presented in details in 2003 [2]. There has been gathe-

\footnotetext{
* Dr inż. Stanisław Ziętarski (s.zietarski@gmail.com); dr hab. inż. Stanisław Kachel (stanislaw.kachel@wat.edu.pl); mgr inż. Abdelkader Benaoual (abdelkader.benaouali@wat.edu.pl) - Wojskowa Akademia Techniczna, Wydział Mechatroniki i Lotnictwa
}

red a considerable experience in the following main areas of applications:

- Analysis of all errors in manufacturing processes, even on the most complex surfaces;

- Effective application of reverse engineering techniques , which is particularly important for airplane shapes;

- Identification of all sources of errors in CAD/CAM/CAE technology;

- Elimination of the necessity of a precise set-up of the measured part on CMMs or other measuring systems;

- Identification a global optimum, among many local optima.

A geometric model of surface concerned, or rather a solid body, is a base for any distance calculation along normals between points and the surface. Due to a large number of points obtained from scanning measurements, the program has an important feature which is the capability of selecting the points from a large data file, keeping almost the same accuracy of the analysis. This is a first layer in an artificial network approach (Fig. 1). Also, the number of combinations can be reduced and it is a second layer in this approach. $10 \%$ of all points and combinations can enable to obtain results with the difference below $4 \%$ in relation to results from the analysis based on the full point set and a deterministic model.

Developed procedures, based on neural network techniques, used in the optimization model of both deterministic and probabilistic modes, are mainly defined by three important values:

- $\mathrm{n}$ - the number of points from coordinate measurements (the first layer in a neural network);

- $\mathrm{m}$ - the space dimension (the number of variables, optimal values of which are searched);

- $k$ - the number of levels for each variable $(k=3,5,7,9$, $11, \ldots$ ), i.e. dimensionless coded values of variables (e.g.: $\mathrm{k}=$ 3 gives coded values: $-1,0,1 ; k=5$ gives coded values: -2 , $-1,0,1,2$ etc.);

- $N_{c}=k^{m}$ - the number of combinations and the size of the second layer in a neural network.

Increments in a program loop $d_{v}(j)$ and code values $i_{v}(j)$ define boundaries (ranges) and real values of variables:

$v(j)_{i}=v(j)_{0}+i_{v}(j) \cdot d_{v}(j)$

Generally, the objective function of the optimization method is to minimize geometric deviations between a virtual product, represented by a CAD model of the product, and a real product after manufacturing, represented by points from measuring systems. 
There are criteria of an accuracy estimation of curves and surfaces, which can be used as the objective function (mostly a standard deviation):

$\sigma=\sqrt{\frac{\sum_{i=1}^{i=n}(d(i))^{2}}{n}} ; \mathrm{t}_{\text {out }}=\frac{\sum_{i=1}^{i=\text { nout }}+d(t)}{\text { nout }} ; \mathrm{t}_{\text {in }}=\frac{\sum_{i=1}^{i i=n i n}-d(t)}{\text { nin }}$

where: $\sigma$ - standard deviation; $t_{\text {out }}, t_{\text {in }}$ - average upper and lower deviation; $+d(i),-d(i)$ - outside and inside distances of points along normal; nout+nin $=\mathrm{n}$ (the number of points)

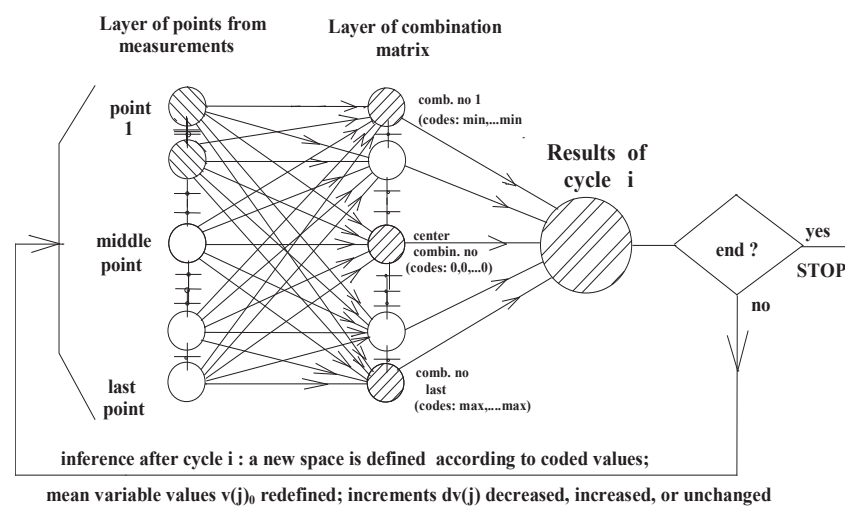

Fig. 1. Combinatorial-cyclic optimization method in artificial neural network concept [2]

\section{CMM accuracy inspection using the CCOpt}

The application of the CCOpt method for the accuracy analysis of CMMs consist of measuring a set of points on the reference sphere (Fig. 2) and submitting their coordinates as input for the optimization algorithm (replacement of the CMM software).
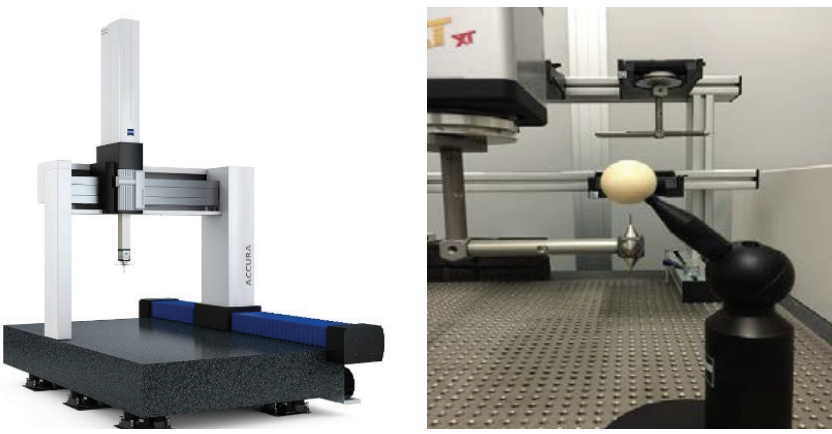

Fig. 2. The reference sphere for the ZEISS ACCURA CMM

Unlike the other objects, applying the CCOpt for the reverse engineering of a sphere doesn't need the geometric model to be built. The distances between points and the surface of the sphere can be determined analytically as follows:

$d_{c}=\sqrt{\left(x_{c}-x_{0}\right)^{2}+\left(y_{c}-y_{0}\right)^{2}+\left(z_{c}-z_{0}\right)^{2}}-R_{c}$

The algorithm will continue to search for design variable optimal values until the desired tolerance is achieved. We hope that the best way to demonstrate the performance of this unique optimization program is to show a fragment of the printout after execution:

\section{FINAL RESULTS \\ ps ( 36): error $=.000042385 \mathrm{~mm}$ \\ ps( 37): error $=.000117283 \mathrm{~mm}$ \\ The max. inside error $=-.000627926$ \\ The max outside error $=.000859333$}

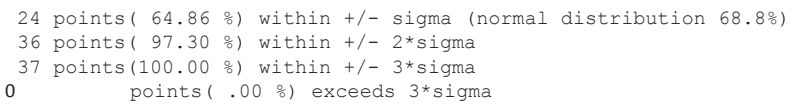

The standard deviation calculated for the best fit sphere is taken as an indicator for the accuracy of the CMM.

\section{Proof of the reliability of the procedure}

In order to prove the reliability of the presented approach, the following steps are carried out:

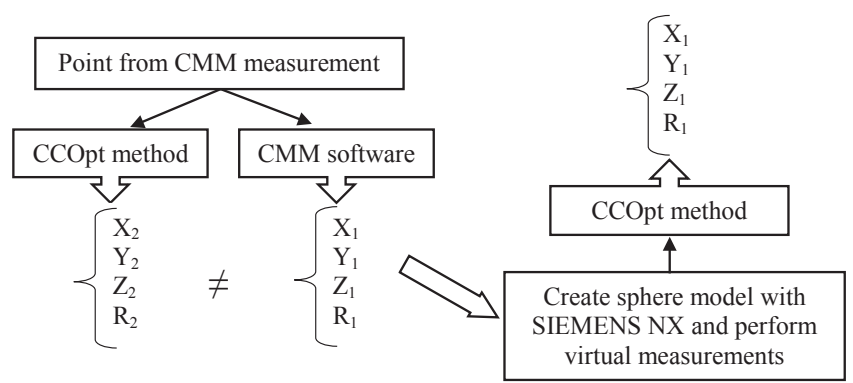

Fig. 3. Steps to prove the reliability of the procedure

It turns out that: $X_{3}=X_{1}, Y_{3}=Y_{1}, Z_{3}=Z_{1}, R_{3}=R_{1}$. With accuracy of $10^{-9} \mathrm{~mm}$. Thus, the results from the CCOpt are meaningfully more accurate.

In order to simplify the use of the presented procedure, a graphical user interface was implemented (Fig. 4). This GUI eases point coordinate input and result access.

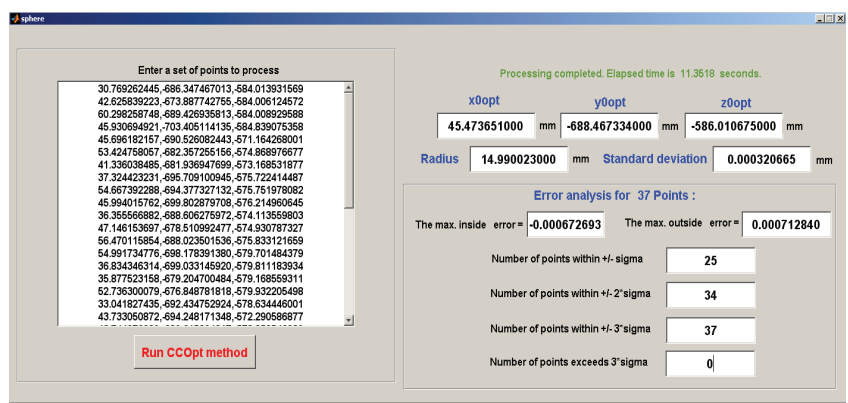

Fig. 4. A graphical user interface implemented for the presented approach

\section{Conclusion}

For the last several years, the combinatorial-cyclic method of optimization has been validated and expanded to new areas of applications. It is becoming a useful and unique tool in design optimization, reverse engineering (parametric design included), and virtual engineering. In this paper, the method was integrated in an original procedure for the analysis of CMM accuracy. The approach proved its reliability and efficiency in a very short processing time thanks to the new generation of computers. The application of presented procedure can be a meaningful factor in speeding-up the whole process toward quality products especially with the increasing computational power of PC and the availability of integrated CAD/CAM/ ICAE systems.

\section{REFERENCES}

1. Mohan P. et al. „Development of a Library of Feature Fitting Algorithms for CMMs". International Journal of Precision Engineering and Manufacturing (2015) Vol. 16, No. 10, pp. 2101-2113.

2. Zietarski S. „Al-based optimization method for the analysis of coordinate measurements within integrated CAD/CAM/CAD systems". Computer Aided Production Engineering, CAPE 2003,Edinburgh. Professional Engineering Publishing Limited, London and Bury St Edmonds, UK, 2003. 